\title{
The relationship between sexual and aggressive behaviour, and pituitary and testicular activity during the seasonal sexual cycle of rams, and the influence of photoperiod
}

\author{
G. A. Lincoln and W. Davidson \\ M.R.C. Unit of Reproductive Biology, 2 Forrest Road, \\ Edinburgh EH1 2QW, U.K.
}

\begin{abstract}
Summary. Six adult Soay rams were housed under artificial lighting conditions, with alternating 16-week periods of long ( $16 \mathrm{~h}$ light: $8 \mathrm{~h}$ darkness) and short days (8L: 16D). During long days the rams were reproductively quiescent : the abrupt change from long to short days induced a specific succession of responses in the reproductive system. Plasma LH and FSH levels began to increase after 2-4 weeks, followed almost immediately by a rise in plasma testosterone levels accompanied by growth of the testes. Testicular activity continued to increase during short days and the greatly elevated androgen levels apparent after 5-10 weeks caused changes in the peripheral target organs, including growth of the epididymides, development of the sexual flush on the exposed ventral skin and heightened genital sensitivity. High testosterone levels were also associated with an increase in aggressive (scored by a mechanical device) and sexual (incidence of Flehmen) behaviour which was at peak about 1 month after the start of the peak androgen levels. The change to long days was associated with a decrease in plasma gonadotrophin levels within 2 weeks followed by a progressive decline in all reproductive parameters measured. Implantation of a low dose of testosterone $(200 \mathrm{mg})$ during the period of reproductive quiescence induced the development of the sexual flush and an increase in genital tactile sensitivity, although behaviour was not significantly affected.

The annual changes in reproductive physiology and behaviour of 12 Soay rams living under natural lighting conditions were recorded for comparison with the experimental situation. The nadir of the sexual cycle was in the spring and early summer, and the sequence of events culminating in the mating season in the autumn was similar to that induced experimentally.
\end{abstract}

\section{Introduction}

Photoperiod is the principal environmental cue which times the reproductive cycle of the domestic ram (Ovis aries): decreasing daylength stimulates reproductive activity and in northern temperate climates, therefore, rams exhibit peak sexual activity in the autumn (Marshall, 1937; Yeates, 1947; Ortavant, Mauléon \& Thibault, 1964). The changes in photoperiod affect reproductive physiology by influencing the release of gonadotrophins from the anterior pituitary. Decreases in daylength stimulate both synthesis and release of LH and FSH (Pelletier \& Ortavant, 1964, 1975), resulting in enhanced spermatogenesis and testosterone production by the testis (Ortavant, 1956; Lincoln, 1976). The increased androgen secretion in turn stimulates the accessory glands of reproduction (Amir \& Volcani, 1965) and affects aggressive and sexual behaviour (Lees, 1965).

Responses to alterations in photoperiod occur fairly rapidly in the pituitary but are more delayed peripherally. For example, the pituitary gonadotrophin content may be affected within 2 days of an abrupt change in photoperiod (Pelletier \& Ortavant, 1964), although it takes weeks of altered photoperiod to affect behaviour (Moule, 1950). These differences in the timing of responses are to be 
expected because they represent changes at different levels in the hierarchy of control which involves hypothalamus, pituitary, testis, peripheral target tissues and behaviour.

The purpose of the present study was to investigate the timing of the responses at these different levels by considering the relationship between pituitary secretion, testicular activity and behaviour. Rams that were in a state of reproductive quiescence were stimulated to full reproductive activity by a change in photoperiod so that the timing of the various responses could be observed. These changes were then compared with the sequence of events that occurs naturally in the seasonal sexual cycle of the ram.

\section{Materials and Methods}

Animals. Soay rams were used because they exhibit pronounced seasonal changes in reproductive physiology (Lincoln, 1976) and behaviour (Grubb \& Jewell, 1973). Six adult rams aged between 3 and 5 years and weighing an average $31.6 \mathrm{~kg}$ were housed in a light-proof building, and provided with a maintenance diet. The animals were individually penned but in auditory, olfactory and visual contact with each other. Artificial daylight was provided by 4 white, fluorescent-strip lights emitting illumination of 140-180 lux/at floor level. The animals received alternating periods of long (16 h light: $8 \mathrm{~h}$ darkness; $16 \mathrm{~L}: 8 \mathrm{D})$ and short (8L: $16 \mathrm{D})$ days each lasting approximately 4 months. The changes in photoperiod were abrupt and were achieved by altering the timing of 'lights out' by $8 \mathrm{~h}$. The rams were preconditioned to the artificial lighting schedule for 1 year, and the present experiment lasted for 10 months from July 1975 . The temperature in the animal house was not controlled and followed the normal seasonal cycle for Edinburgh.

Collection of data. Blood samples were collected into Vacutainers (Beckton Dickinson) from the jugular vein of each ram three times weekly, usually between 08.00 and $09.00 \mathrm{~h}$. The plasma was separated immediately and stored at $-20^{\circ} \mathrm{C}$ until assayed for $\mathrm{FSH}, \mathrm{LH}$ and testosterone. Once or twice weekly the shortest diameter of the testes was measured using callipers held across the gonad within the scrotum. On these occasions the cauda epididymidis was palpated, and its size estimated using callipers. The diameter of the free end of the penis sheath was also measured. The bare skin on the abdomen immediately anterior to the scrotum, and on the inside of the hind legs was inspected for signs of hyperaemia; reddening of the skin only occurred in the sexually active rams and was rated on an intensity scale of 0-5 using a colour code. The tactile sensitivity of the skin in the area of the testes was recorded by observing the animal's response to gentle manipulation of the scrotum close to the shaft of the penis; in the sexually active rams this resulted in the penis sheath being rapidly flicked back and forth, sometimes leading to an erection. The response was rated on an arbitrary scale of $0-5$. All these observations were made by the same observer.

An index of aggressive behaviour of the rams was obtained by using mechanical counters positioned inside each animal's pen. The device consists of a mobile percussion bar fixed about $0.5 \mathrm{~m}$ above the ground and alongside the railing of the adjacent animal's pen; some pens had two such bars. One end of the bar was fixed to a pivot while the other was free to swing against a tally counter anchored in position. Counts were recorded when the bars were knocked out of the resting position by rams attempting to fight their neighbours. Observations lasting for $15 \mathrm{~h}$ from a hide in the animal house showed that over $80 \%$ of the counts recorded resulted from such interactions, and this behaviour was closely correlated with other aggressive actions such as pawing at the bedding with the fore-feet, lateral presentation of the body to the opponent, and tooth grinding.

Throughout the study notes were taken of other aspects of behaviour, including pawing the bedding into a heap away from a neighbour, and threatening behaviour towards the observer. At no stage did the rams have contact with ewes; the only aspect of sexual behaviour recorded from the animals was the occurrence of Flehmen (Hafez, Cairns, Hulet \& Scott, 1969).

At the end of the study two of the rams were given implants of heat-fused crystalline testosterone $(2 \times 100 \mathrm{mg}$ : Organon) placed subcutaneously on the inside of the thigh of the hind leg. Observations on these animals were continued for a further 2 months.

Control rams. A group of 12 adult Soay rams aged between 3 and 6 years were kept outside under 
natural lighting for comparison with the experimental group detailed above. These were free to graze in a small paddock at the Dryden Field Station close by the housed animals, and received supplementary feeding of hay and turnips only in the winter. They were brought into a handling area by sheep dogs at monthly intervals over a period of 1 year and single blood samples were collected into Vacutainers. At this time the testicular diameter was measured as described above and the extent of the sex flush recorded. Occasional notes were made on the aggressive behaviour of the rams while in the paddock and handling area, and the overall frequency of aggression was rated on a scale of 0-4.

Radioimmunoassays. Plasma LH levels were determined by a specific double-antibody radioimmunoassay (Scaramuzzi, Caldwell \& Moor, 1970) using an antiserum against ovine LH (NIHLH-S12) raised in a rabbit (Martensz, Baird, Scaramuzzi \& Van Look, 1976) and a Reichert preparation of ovine LH (LER 137A) for iodination. The inter- and intra-assay variation was $12 \%$ and $8.1 \%$, respectively. The sensitivity was $0.05-0.075 \mathrm{ng} /$ tube. FSH levels were measured by a heterologous radioimmunoassay (Lincoln, Peet \& Cunningham, 1977) using an antiserum against ovine FSH (NIH-FSH-S9) raised in a rabbit, and a rat FSH preparation (NIH-Rat FSH-13) for iodination. The assay had a significant but low cross-reaction with ovine LH ( $8.5 \%$ NIH-LH-S14) and minimal cross-reactions with ovine TSH $(<2.0 \%$ NIH-TSH-S 8$)$, ovine prolactin $(<0.01 \%$ NIH-P-S9) and ovine growth hormone $(<0.1 \% \mathrm{NIH}-\mathrm{GH}-11)$. The intra-assay variation was $3.4 \%$. Testosterone determinations were by the specific radioimmunoassay of Corker \& Davidson (1977); the inter- and intra-assay variation was $11.5 \%$ and $<6 \%$, respectively, and the sensitivity was $8 \mathrm{pg} /$ tube.

\section{Results}

The results for one of the rams (S2) are shown in Text-fig. 1 and are typical of those obtained for the other 5 animals. At the beginning of the study (long days) the rams were sexually quiescent with low plasma LH and FSH levels, small testes secreting little testosterone, and few signs of peripheral androgen stimulation. The change to short photoperiods (Week 0 ) induced a sequence of responses as summarized in Table 1 and Text-fig. 2.

The peak in testicular function occurred towards the end of the 4-month period of short daylengths. The peak in aggressive and sexual behaviour occurred at least 1 month later. At this time the cauda

Table 1. Summary of the timing of various reproductive characteristics (see text), recorded in 6 Soay rams after a change from long (16L:8D) to short daylengths (8L:16D)

\begin{tabular}{|c|c|c|}
\hline & \multicolumn{2}{|c|}{$\begin{array}{l}\text { Interval (weeks) from beginning of } \\
\text { short daylengths }\end{array}$} \\
\hline & Initial response & Peak response \\
\hline \multicolumn{3}{|l|}{ Pituitary responses } \\
\hline Plasma FSH levels & $2-4$ & $5-9$ \\
\hline Plasma LH levels & $2-4$ & $3-8$ \\
\hline \multicolumn{3}{|l|}{ Testicular responses } \\
\hline Testicular diameter & $2-5$ & $10-18$ \\
\hline Plasma testosterone levels & $3-6$ & $11-17$ \\
\hline \multicolumn{3}{|l|}{ Target organ responses } \\
\hline Cauda epididymidis size & $5-8$ & $11-18$ \\
\hline Penis sheath diameter & $6-10$ & $11-18$ \\
\hline 'Sexual flush' & $5-8$ & $9-11$ \\
\hline Genital sensitivity & $5-8$ & $11-18$ \\
\hline Aggressive behaviour index & $8-14$ & $17-21$ \\
\hline Occurrence of Flehmen & $10-18^{*}$ & $19-21^{*}$ \\
\hline
\end{tabular}

*1 ram failed to show Flehmen. 


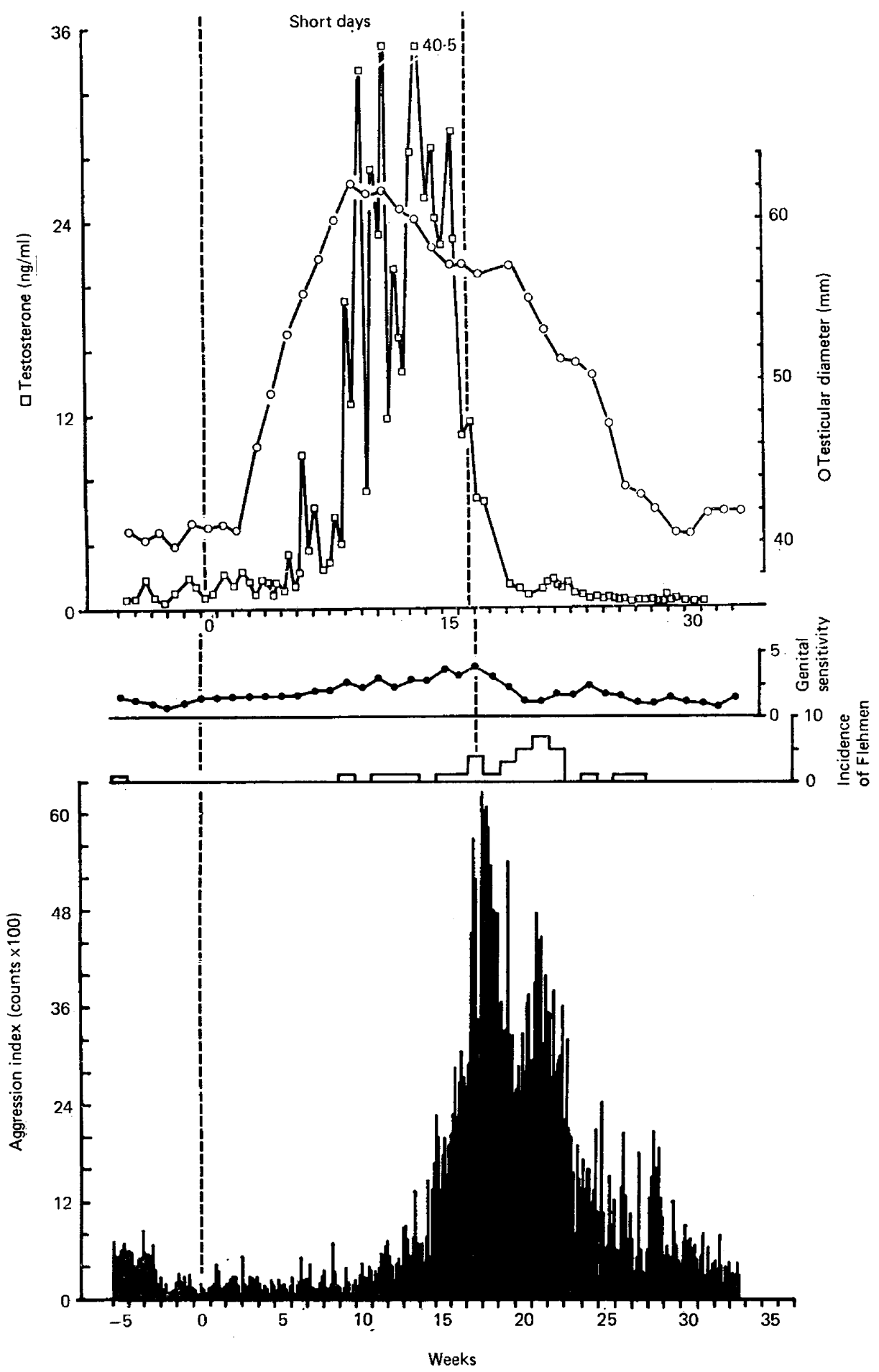

Text-fig. 1. The changes in various reproductive characteristics (see text) in Ram S2 during the 36-week study of alternating periods of long (16 h light: $8 \mathrm{~h}$ darkness) and short ( $8 \mathrm{~h}$ light: $16 \mathrm{~h}$ darkness) days. The changes from long to short daylength occurred at Week 0 and from short to long at Week 16. 


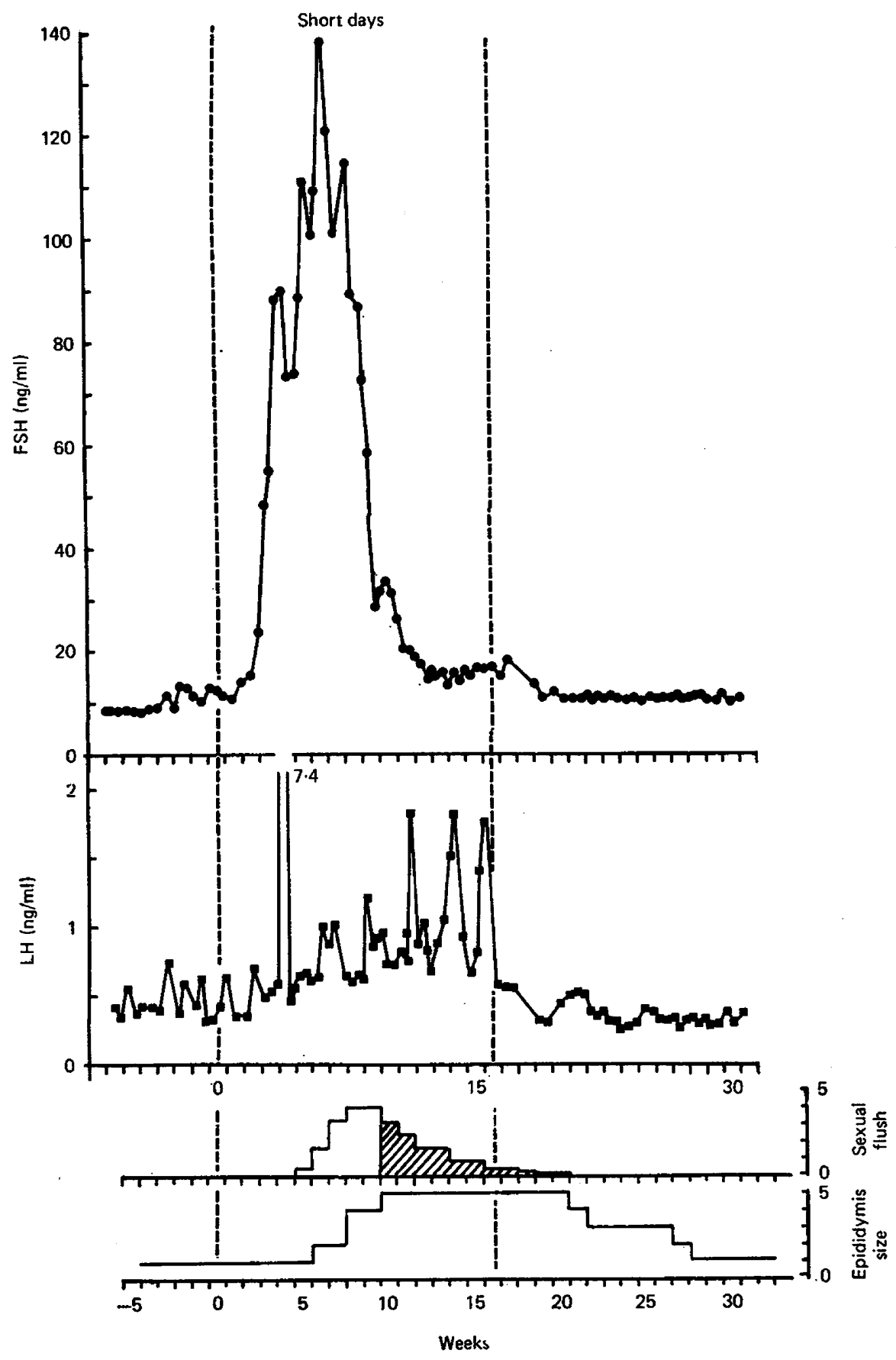

Text-fig. 1-continued 


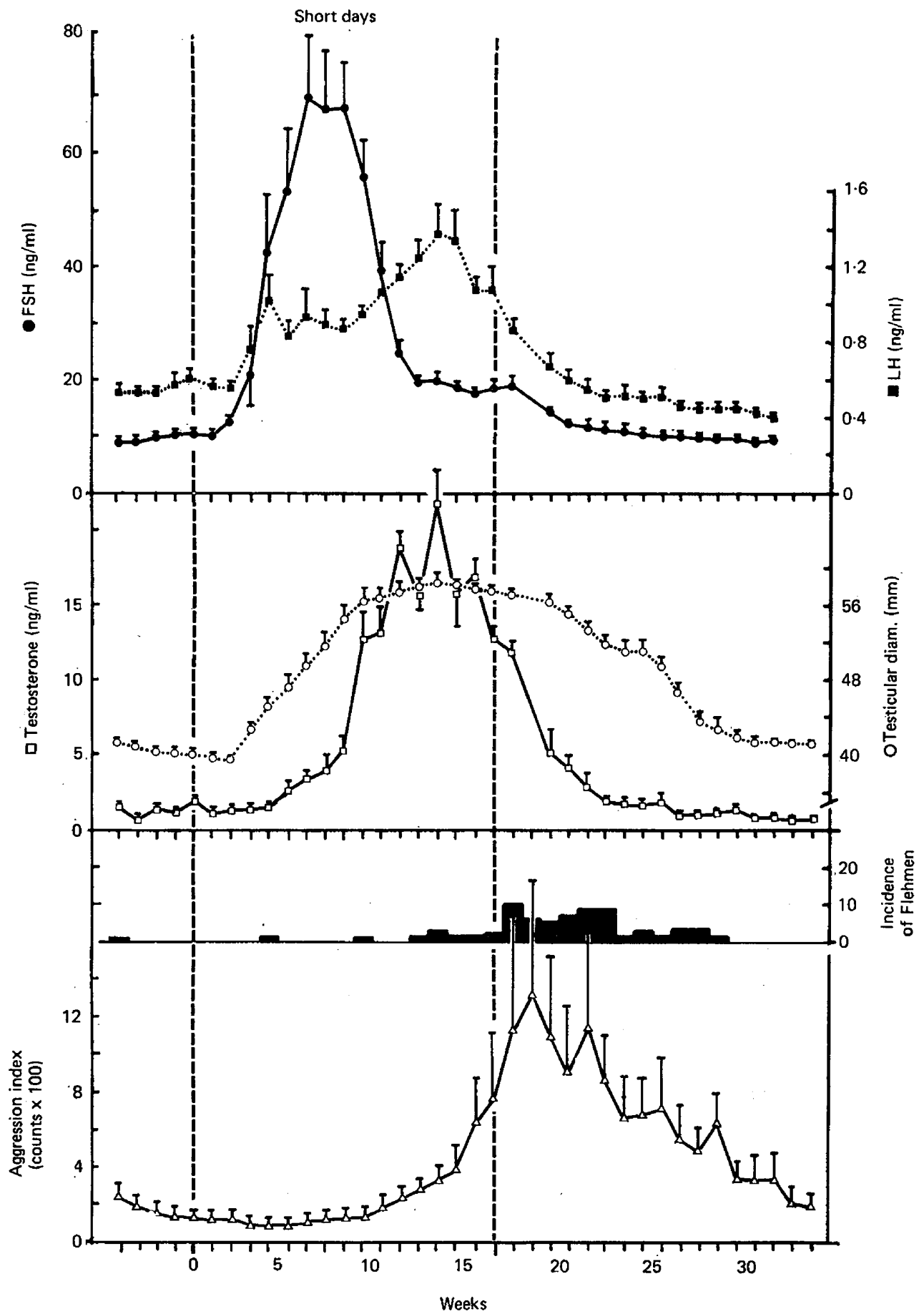

Text-fig. 2. Plasma FSH, LH and testosterone levels, testicular diameters and aggression scores (weekly mean \pm S.E.M.) for 6 Soay rams housed under artificial lighting conditions. The total weekly observations of Flehmen are also shown. The timing of the light changes was as in Text-fig. 1. 
epididymidis was still distended, the end of the penis sheath was swollen and the tactile sensitivity of the genitalia was greatly elevated. However, the sexual flush of the skin close to the scrotum was diminished, having gradually changed from red to purple and become pale. The rams were restless, often pawing their bedding into one corner of the pen; they were more resistant to being handled, and frequently threatened the observer.

The return to long daylengths suppressed gonadotrophin secretion and resulted in involution of the testes and a slow return to reproductive inactivity. Implantation of testosterone $(200 \mathrm{gm})$ in 2 rams at the reproductively quiescent stage resulted in the reappearance of the sexual flush within 4 weeks, initially on the side of the implant (Text-fig. 3) and subsequently became more widespread. The tactile sensitivity of the genitalia also increased but the aggression index did not change significantly, and Flehmen was not exhibited. Plasma levels of testosterone during the treatment were generally
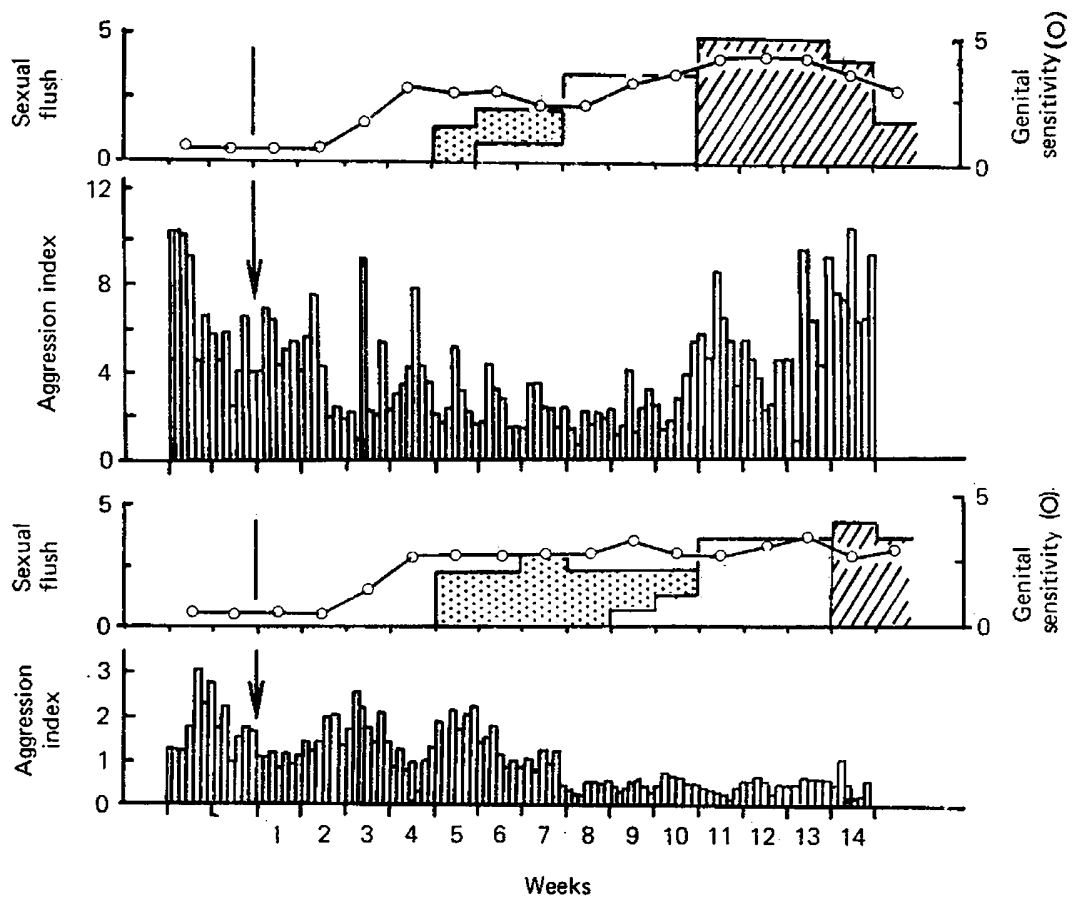

Text-fig. 3. The intensity of the sexual flush, genital tactile sensitivity and aggressive behaviour of two Soay rams after the implantation of $200 \mathrm{mg}$ testosterone (arrow) during a period of sexual quiescence. Because of the unilateral implantation the sexual flush appeared locally at first (stippled histograms). The hatched histograms indicate the period when the sexual flush changed from red to purple and began to fade.

1-2 $\mathrm{ng} / \mathrm{ml}$ and occasionally higher, representing elevation from the normal level at this stage of the reproductive cycle but being only about one-tenth of the level naturally achieved at the peak of testicular activity.

Control rams. The results for the Soay rams living under natural lighting conditions are shown in Text-fig. 4. These rams were sexually quiescent in the spring, but reproductive activity began in June with an increase in gonadotrophin levels and growth of the testes. Full testicular size and maximum plasma testosterone levels occurred by October. The sex flush was most conspicuous in September, while aggressive behaviour amongst the rams became progressively more evident from August, reaching a peak in November. Flehmen was also frequent in November, and the rams often attempted to escape from their paddock to join ewes. During the autumn mating period, gonadotrophin levels began to decrease and a further decline to low levels in the winter led to testicular involution. Aggressive and sexual behaviour of the rams declined slowly through the winter. 


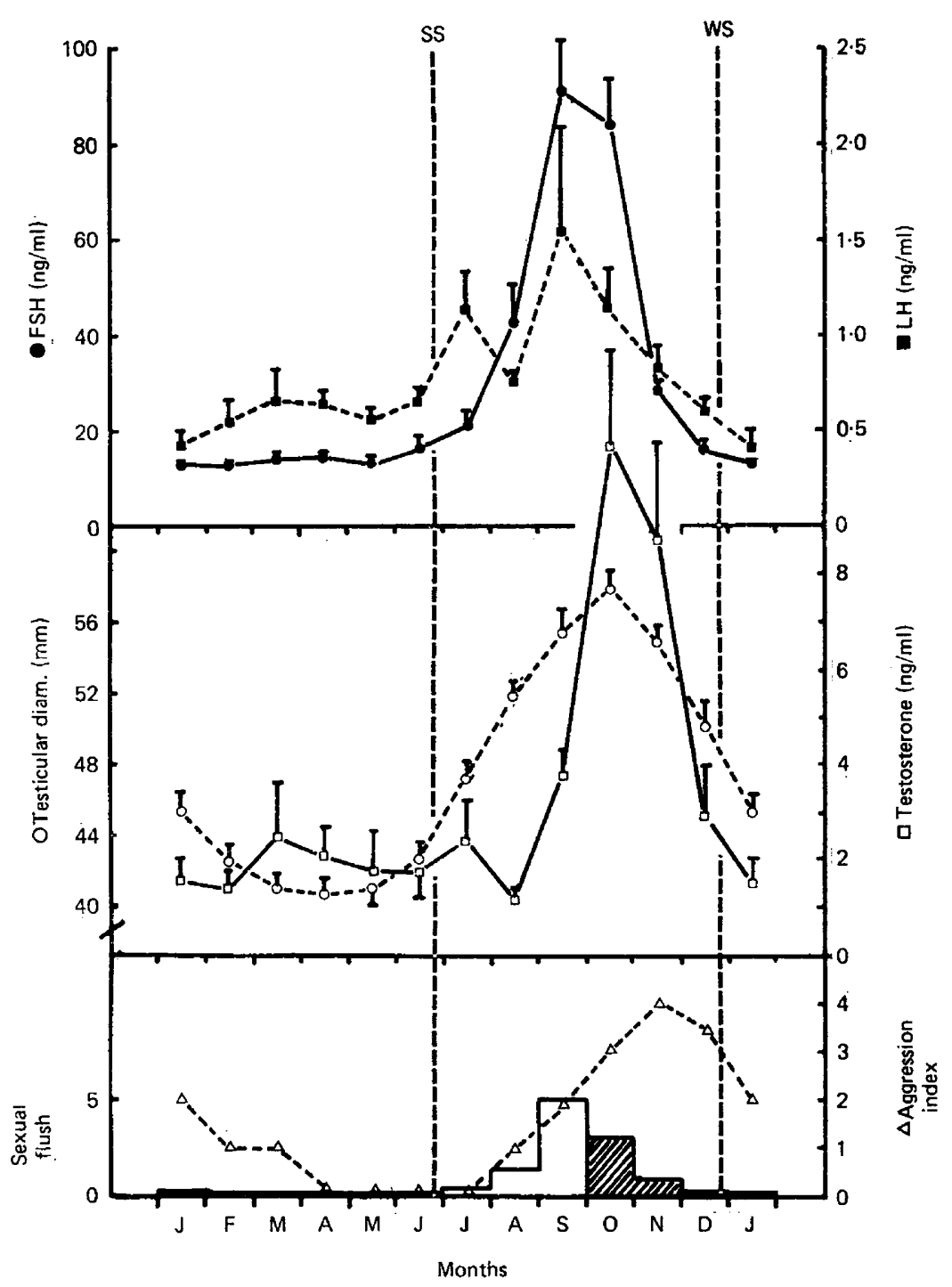

Text-fig. 4. The changes (monthly mean \pm S.E.M.) of various reproductive characteristics of 12 adult Soay rams living under natural lighting conditions for 1 year. $\mathbf{S S}=$ summer solstice; $\mathrm{WS}=$ winter solstice.

\section{Discussion}

The artificial light regimen used in the present study induced a cycle of changes in the reproductive system of the rams similar to that which occurs naturally in relation to season. The change from long to short days stimulated pituitary secretion of LH and FSH, while that from short to long days had the reverse effect. This experimental evidence supports the view that photoperiod plays a dual role in influencing the seasonal sexual cycle of the ram, stimulating or suppressing activity according to the time of year.

When rams are reproductively quiescent because of the long days, an abrupt transfer to short days induces a specific sequence of responses (Table 1); gonadotrophin levels increase within a few weeks leading to testicular growth and increased testosterone secretion. As a consequence the androgen 
target tissues are stimulated and sexual and aggressive behaviour are affected. The present results confirm that changes at the level of the central nervous system and pituitary can occur rapidly in response to changes in photoperiod, while more peripheral responses are delayed: full sexual activity was not restored for 4-5 months in spite of the initial fairly rapid response to the stimulus of short days.

The artificial light regimen used in this study involved a light change every 4 months and peak sexual activity therefore occurred early in the period of long days. The long interval required to achieve full sexual development meant that there was a limit to the extent to which the seasonal sexual cycle could be accelerated by the artificial light schedule. The 8 -month light cycle used in the present study was adopted since it was the shortest period during which complete sexual development followed by regression could be achieved. Under natural conditions in the Northern hemisphere the longest day of the year occurs at the summer solstice (midsummer day $=22$ June); before this date daylength is gradually increasing and afterwards it is decreasing. Rams living under natural conditions reach peak sexual activity 4-5 months after the summer solstice. This is the same interval as that observed in the experimental rams and suggests that the nature of the light change (gradual or abrupt) does not grossly affect the timing of the sequence of events.

One of the intriguing features of the natural cycle of the ram is that the developmental changes before the mating season tend to begin slightly before the summer solstice when daylength is long and increasing (Text-fig. 4). This apparent contradiction of the role of light in stimulating reproductive activity may be explained, however, by the fact that gonadotrophin secretion will begin to increase again without apparent cause in rams maintained on constant long days for a prolonged period. As has been shown in the present study, the initial effect of long days after short days is to suppress gonadotrophin secretion to low levels for 2-3 months. After this, the animals begin to recover from the suppressive influence of light and plasma gonadotrophin levels start to increase (Lincoln $e t$ al., 1977). In the same way as the suppressive effects of long days appear to fade after a few months, so also do the stimulatory effects of short days. In the experimental rams gonadotrophin levels began to decline after 2-3 months of short days even though the stimulatory photoperiods were maintained. This is similar to the situation which occurs before the winter solstice in rams kept in natural daylength.

Apart from the spontaneous changes in gonadotrophic activity, some explanation must be found for the existence of spontaneous cycles of testicular activity which occur in constant photoperiods. In some seasonally breeding animals testicular cycles of approximately 1 year in duration occur in the absence of photoperiodic cues (Goss \& Rosen, 1973; Gwinner, 1975; Pengelley \& Asmundson, 1974; Berthold, 1974; Michael \& Bonsall, 1977). Such changes are difficult to explain in terms of a waxing and waning sensitivity to photoperiod and other explanations, e.g. cyclic changes in the sensitivity to androgen feedback at the hypothalamic levels related to a slowly changing level of circulating androgens, must be sought. Limited data on Soay sheep indicate that spontaneous reproductive cycles can also occur in this species, and it may therefore be necessary to envisage the role of the photoperiod in sheep as being to control the time of the sexual cycle rather than the cause of it. In natural conditions with a seasonally changing photoperiod, the stimulatory (autumn) and inhibitory (spring) effects of daylength described above would operate to entrain the cycle to the changes in the environment.

This work was carried out at the Dryden Field Laboratory near Edinburgh and we thank the Animal Breeding Research Organization for the use of their facilities, and Mrs. R. Cunningham and Mr M. Peet for their help. Dr J. Uilenbroek and Dr R. Scaramuzzi generously provided antisera for use in the radioimmunoassays, and we are indebted to the Endocrine Study Section of the NIH, Bethesda, for the standard preparations of ovine FSH and LH.

\section{References}

AmiR, D. \& Volcani, R. (1965) Seasonal fluctuations in the sexual activity of Awassi, German Mutton, Corriedale, Border Leicester and Dorset Horn rams.
1. Seasonal changes in semen volume and its fructose and citric acid concentrations. J. agric. Sci., Camb. 64, 115-120. 
Berthold, P. (1974) Circannual rhythms in birds with different migatory habits. In Circannual Clocks, pp. 55-95. Ed. E. T. Pengelley. Academic Press, New York.

Corker, C.S. \& DAvidson, D. (1977) The radioimmunoassay of testosterone in various biological fluids without chromatography. J. Steroid Biochem. (in press).

Goss, R.J. \& RoseN, J.K. (1973) The effect of latitude and photoperiod on the growth of antlers. $J$. Reprod. Fert., Suppl. 19, 111-118.

GrubB, P. \& Jewell, P.A. (1973) The rut and the occurrence of oestrus in the Soay sheep on St. Kilda. J. Reprod. Fert., Suppl. 19, 491-502.

GwinNer, E. (1975) Circadian and circannual rhythms in birds. In Avian Biology, pp. 221-285. Eds D. S. Farner \& J. R. King. Academic Press, New York.

Hafez, E.. Cairns, R., Hulet, C. \& ScotT, J. (1969) The behavior of sheep and goats. In The Behavior of Domestic Animals, pp. 296-348. Ed. E. S. E. Hafez. Williams \& Wilkins, Baltimore.

LEES, J. (1965) Seasonal variation in the breeding activity of rams. Nature, Lond. 207, 221-222.

Lincoln, G.A. (1976) Seasonal variation in the episodic secretion of luteinizing hormone and testosterone in rams. J. Endocr. 69, 213-226.

Lincoln, G.A., Peet, M.J. \& Cunningham, R.A. (1977) Seasonal and circadian changes in the episodic release of FSH, LH and testosterone in rams exposed to artificial photoperiods. J. Endocr. (in press).

Marshall, F.H.A. (1937) On the change over in the oestrous cycle in animals after transference across the equator, with further observations on the incidence of the breeding seasons and the factor controlling. sexual periodicity. Proc. $R$. Soc. B. 122, 413-428.

Martensz, N.D., Baird, D.T., Scaramuzzr, R.J. \& VAN Look, P.F.A. (1976) Androstenedione and the control of luteinizing hormone in the ewe during anoestrus. J. Endocr. 69, 227-237.

Michael, R.P. \& Bonsall, R.W. (1977) A 3-year study of an annual rhythm in plasma androgen levels in male rhesus monkeys (Macaca mulatta) in a constant laboratory environment. J. Reprod. Fert. 49, 129-131.

Moure, G.R. (1950) The influence of rapid decreases in the hours of daylight on the sexual desire of merino rams. Aust. vet. J. 26, 84-87.

Ortavant, R. (1956) Action de la durée d'éclairement sur les processus spermatogenetiques chez le bélier. C. r. Séanc. Soc. Biol. 150, 471-474.

Ortavant, R., Mauléon, P. \& Thibault, C. (1964) Photoperiodic control of gonadal and hypophyseal activity in domestic animals. Ann. N.Y. Acad. Sci. 117, 157-193.

Pelletier, J. \& Ortavant, R. (1964) Influence de la durée d'éclairement sur le contenu hypophysaire en hormone gonadotropes FSH et ICSH chez Ie bélier. Annls Biol. anim. Biochim. Biophys. 4, 17-26.

Pelletier, J. \& Ortavant, R. (1975) Photoperiodic control of LH release in the ram. I. Influence of increasing and decreasing light photoperiods. Acta endocr., Copenh. 78, 435-441.

Pengelley, E.T. \& Asmundson, S.J. (1974) Circannual rhythmicity in hibernating mammals. In Circannual Clocks, pp. 95-160. Ed. E. T. Pengelley. Academic Press, New York.

Scaramuzzi, R.J., Caldwell, B.V. \& Moor, R.M. (1970) Radioimmunoassay of LH and estrogen during the estrous cycle in the ewe. Biol. Reprod. 3, 110-119.

YEATES, N.T.M. (1947) Influence of variation in length of day upon the breeding season of sheep. Nature, Lond. 160, 429-430.

Received 30 July 1976 